\title{
Mengovirus as Process Control Virus in the Monitoring of Genomic RNA and Infectivity of Enteric Viruses in Water Matrices
}

\author{
Daniel Salvador ${ }^{1,2,3, *(\mathbb{C}}$, Célia Neto ${ }^{2}$, Rui Neves Carneiro ${ }^{2}\left(\mathbb{D}\right.$ and Maria Filomena Caeiro ${ }^{3}(\mathbb{D}$ \\ 1 Instituto de Saúde Ambiental, Faculdade de Medicina da Universidade de Lisboa, Avenida Professor Egas \\ Moniz, 1649-028 Lisboa, Portugal \\ 2 Direção de Laboratórios (LAB), Empresa Portuguesa das Águas Livres (EPAL), Avenida de Berlim, 15, \\ 1800-031 Lisboa, Portugal; celianet@adp.pt (C.N.); rcarnei@adp.pt (R.N.C.) \\ 3 Departamento de Biologia Vegetal, Faculdade de Ciências da Universidade de Lisboa \& CESAM-Centro de \\ Estudos do Ambiente e do Mar, Universidade de Aveiro, 3810-193 Aveiro, Portugal; mfcaeiro@fc.ul.pt \\ * Correspondence: daniel.salvador@adp.pt
}

Citation: Salvador, D.; Neto, C.;

Carneiro, R.N.; Caeiro, M.F.

Mengovirus as Process Control Virus in the Monitoring of Genomic RNA and Infectivity of Enteric Viruses in Water Matrices. Water 2021, 13, 2834. https://doi.org/10.3390/w13202834

Academic Editor: Athena Mavridou

Received: 31 August 2021

Accepted: 7 October 2021

Published: 12 October 2021

Publisher's Note: MDPI stays neutral with regard to jurisdictional claims in published maps and institutional affiliations.

Copyright: (C) 2021 by the authors. Licensee MDPI, Basel, Switzerland. This article is an open access article distributed under the terms and conditions of the Creative Commons Attribution (CC BY) license (https:/ / creativecommons.org/licenses/by/ $4.0 /)$.

\begin{abstract}
The present study, developed in the scope of a survey to monitor enteric viruses in natural surface water and drinking water sources, addressed the suitability of mengovirus to assess viral recovery rates at two steps of the water sampling process. In a pilot campaign comprising two samples from each type of water source, when mengovirus was added after the filtration/primary concentration step, the recovery rates of viral RNA were higher than $18 \%$ and identical for both water matrices. In a one-year sampling campaign, where mengovirus was present along the whole sample processing (addition in the filtration/primary concentration step), significantly different recovery rates were observed between water matrices: usually higher than $1 \%$ in drinking water and under $1 \%$ in surface water. The results suggest the first stage of the water sampling process and the type of water matrix are the most influential factors for viral RNA recovery. This study also addressed and evidenced mengovirus replication and titration in Vero E6 cultures and showed infectious mengovirus to be recovered from samples of both types of water matrix. These results anticipate a more comprehensive applicability of mengovirus as a process control virus in the monitoring of viruses in water, extended to viral infectivity.
\end{abstract}

Keywords: drinking water; enteric viruses; environmental monitoring; method 1615; RT-qPCR; surface water; viral infectivity; virus titration; water quality; water treatment

\section{Introduction}

Water safety is essential in today's societies [1]. From this perspective, the monitoring of this resource is essential to avoid exposure to pathogenic agents [2-4], whose presence in drinking water production and distribution systems can have a high impact on public health; not only health may be affected but also the consumers' confidence in the water that is provided [2]. Water can be contaminated by bacteria, protozoa, and viruses $[2,4,5]$. Of the several pathogens, it is worth highlighting enteric viruses, classified by the World Health Organization (WHO) as having a moderate to high impact on human health [1].

In the 21st century, enteric viruses still one of the main causes of mortality and morbidity worldwide [1,5]. In nature, there are more than 200, distributed across different families such as, for example, Adenoviridae, Astroviridae, Caliciviridae, Hepeviridae, Reoviridae, and Picornaviridae. They replicate in the gastrointestinal tract and are transmitted mainly through the fecal-oral route [5], where contaminated water and food are the main transmission vehicles. Water contamination can occur in different ways, namely through disruptions in sewerage networks, untreated wastewater discharges, industrial waste discharges, open defecation, ship discharges in ports and surface runoff [2-6]. These pathogens are released in large numbers in the feces of carriers during infection, being 
more resistant than bacteria to changing environmental conditions (e.g., temperature and $\mathrm{pH}$ ) [4-6]. They can maintain the ability to infect living organisms for long periods of time in water. The presence of robust capsids and the absence of lipid envelopes make them highly resistant to water disinfection treatments [5,7]. Their elimination is thus complex in water matrices [8]. When entering the bodies of humans or other animals, they can cause a diverse range of symptoms such as gastroenteritis, fever and, in extreme cases, death [6].

Over the years, enteric viruses have been detected both in developing and developed countries such as Portugal, France, the United States, the Netherlands, and Germany, in various water matrices, namely natural water (surface water and groundwater), drinking water, and wastewater $[4,5,8]$.

The methodologies for the monitoring of these viruses are complex, in most cases with low recovery rates [9-11]. Two of the most commonly applied methodologies are the Method 1615 of the United States Environmental Protection Agency (EPA) [12] and the European methodology ISO 15216-1: 2017 [13]. Method 1615 allows the analysis of large volumes of water (from some milliliters to more than $1500 \mathrm{~L}$ ), which results in greater security for the analysis and for the water consumers, and which was therefore followed in this study [12]. The high complexity of the method, consisting of different steps (filtration/primary concentration, secondary concentration, tertiary concentration, extraction of nucleic acids, molecular detection and quantification) may take advantage of the utilization of a process control virus, to allow estimating the recovery rate of the viruses present in the sampled water, usually quantified by reverse transcription coupled to quantitative polymerase chain reaction (RT-qPCR) [9,14,15].

Currently, there are several process control viruses on the market to assess the efficiency of other viruses' recovery during sample processing and the possible inhibition of RT-PCR reactions [9,14]. Among the various available controls, the most common are mengovirus, murine norovirus, feline calicivirus, MS2 coliphage, Tulane virus, and turnip crinkle virus [14].

One of the most commercialized is the vMC0 strain of mengovirus (Cardiovirus A, according to the ICTV 2019 Release), which is a member of the Picornaviridae [16]. The non-virulent mutant vMC0 strain of mengovirus was patented in 2007 by Barcelona University as control of the nucleic acids' extraction step (PCT/EP2007/055407) [17]. This virus has structural and physical-chemical properties similar to those of hepatitis A virus (an enteric virus), and resistance in the environment similar to most enteric viruses, which make it a current morphological, physical-chemical, and genetic model for virus' monitoring [15,18-20].

Mengovirus is also referenced in the European standard ISO 15216-1: 2017 as the process control virus of the method for detection of hepatitis A virus and noroviruses by quantitative RT-qPCR [13]. In recent years, mengovirus has been used not only as control of the RNA extraction step but also in other phases of the sampling processes prior to RNA extraction, in studies involving a diversity of samples (berries, lettuce, and bivalves), in addition to water (drinking water and wastewater) [15,21-23]. In the study of HennechartCollette et al. [24] comprising water and food samples, mengovirus was considered the most appropriate control for the detection of Norovirus Genogroup I in bottled water and semi-dried tomatoes; on the other hand, murine norovirus type 1 was considered the most suitable for the detection of hepatitis A virus and Norovirus Genogroup II in lettuce. Similar conclusions were reached in the study of Gentry-Shields and Jaykus [14], where five process control viruses (mengovirus, murine norovirus, MS2 coliphage, Tulane virus, and turnip crinkle virus) were evaluated, and mengovirus showed recovery rates closer to those of human Norovirus in food samples. In 2020, mengovirus was used as a process control virus for the detection of genomic RNA of Enterovirus, hepatitis A virus, hepatitis E virus and Norovirus, in diverse water matrices: groundwater and surface water intended for drinking water production, drinking water, and wastewater $[8,15,18]$. More recently, mengovirus was also used as a process control virus in the monitoring of SARS-CoV-2 (an enveloped RNA virus) in drinking water and wastewater [22,25,26]. 
The recovery rates of mengovirus were very variable, from $48.75 \%$ and $36.3 \%$ in bottled water (Coudray-Meunier et al. [21] and Hennechart-Collette et al. [24], respectively), to lower values in residual water, as in the study by Randazzo et al. [22] where the recoveries varied between $3.3 \pm 1.6 \%$ in influent water and $6.2 \pm 1.0 \%$ in effluent water $[21,22,24]$.

The present study, involving two water matrices (surface and drinking water) surveyed for the presence of enteric viruses, aimed to evaluate the suitability of mengovirus as process control virus in the water sampling process carried out in these surveys. The recovery of mengovirus was evaluated for its addition before and after the filtration/primary concentration, i.e., the presence of the control virus during the whole sampling process or only in the final stages after filtration. The final step was viral RNA detection and quantification (for all samples) and evaluation of viral infectivity (only for some samples).

This study also addressed the suitability of mengovirus as control virus in surveys targeting viral infectivity, by making use of Vero E6 cell cultures where the virus was produced and titrated. A consequence of this approach was the assessment of mengovirus infectivity carried out in some samples.

\section{Materials and Methods}

\subsection{Collection, Filtration, and Concentration of Water Samples}

In two sampling campaigns, carried out in May 2018 and January-December 2019, surface water and drinking water were surveyed for a group of enteric viruses (Enterovirus, HAV, HEV and Norovirus), by the application of Method 1615 [12]. The surface water was collected in a river and in a dam reservoir. Drinking water was collected at the outlet of two Water Treatment Plants (WTPs) and at a point in the distribution network. WTP_R treats natural water from the river $(\mathrm{R})$ and WTP_D treats natural water from the dam reservoir (D). In the distribution network, there is a mixture of water coming from the two WTPs. The characteristics of the sampling sites and the filtration and concentration procedures were described in Salvador et al. [23]. In short, 10 to $1500 \mathrm{~L}$ of surface water and 600 to $1900 \mathrm{~L}$ of drinking water were collected by filtration/concentration at the sampling sites, using Nanoceram ${ }^{\circledR}$ filters (Argonite; Sanford, FL, USA), at a maximum filtration flow of $10 \mathrm{~L} /$ minute. For surface water, the filtration/primary concentration occurred until the filter clogged, or the sampled volume was greater than $100 \mathrm{~L}$ (not exceeding five hours). For drinking water, the filtration/primary concentration was carried out until the sampled volume was greater than $500 \mathrm{~L}$ (not exceeding seven hours). The filters were then transported in refrigerated chests to the laboratory, inside glass housings filled with $500 \mathrm{~mL}$ of water. This volume of water was filtered in the laboratory, just before eluting the filter concentrates with 3\% beef extract (BD Bioscience; Franklin Lakes, NJ, USA). Then, the eluted samples went through an organic flocculation process involving centrifugations (secondary concentration) and followed by filtration through $0.22 \mu \mathrm{m}$ pore-size Acrodisc Syringe filters (PALL Corporation; Ann Arbor, MI, USA) to remove bacteria and fungi [21]. After these procedures, the resulting samples of about $35 \mathrm{~mL}$ were aliquoted and frozen at $-70^{\circ} \mathrm{C}$. A subsample of $10 \mathrm{~mL}$ was reserved for infectivity assays in Vero E6 cultures as described in Salvador et al. [23]. A subsample of $20 \mathrm{~mL}$ reserved for RNA extraction undergone a tertiary concentration in Vivaspin ${ }^{\circledR}$ concentrators (Sartorius; Goettingen, Germany) by centrifugation at $8000 \times g$ and $4{ }^{\circ} \mathrm{C}$ for $6 \mathrm{~h}$ or until a volume of about $1 \mathrm{~mL}$ was achieved. RNA was then extracted from this concentrated $[10,23]$.

\section{Mengovirus Addition}

In the pilot samplings of May 2018, $10 \mu \mathrm{L}$ (corresponding to $10^{6}$ genomic copies) of a mengovirus solution (bioMérieux; Marcy-l'Etoile, France) was added to the $3 \%$ beef extract before the starting of the organic flocculation (secondary concentration) referred at previous point.

In the 2019 campaign, aiming to cover all of the experimental procedures, $10 \mu \mathrm{L}$ of a mengovirus solution ( $10^{6}$ genomic copies) (bioMérieux; Marcy-l'Etoile, France) was added to the lasting volume of water $(500 \mathrm{~mL}$ transported in the housing with the filter) that was 
filtered just before the elution of the filter concentrates (secondary concentration step) as referred above.

\subsection{RNA Extraction, Mengovirus RNA Detection and Quantification by RT-qPCR}

RNA extractions from the concentrated water samples (Section 2.1) were performed with the QIAamp viral RNA Mini kit (Qiagen; Hilden, Germany), following the manufacturer's instructions. RT-qPCR reactions targeting the detection and quantification of mengovirus genomic RNA were performed on a StepOnePlus thermocycler (Applied Biosystems; Foster City, CA, USA), according to the conditions described in Salvador et al. [10,23]. In short, Mengovirus Extraction Control kit (bioMérieux; Marcyl'Etoile, France), was used in $25 \mu \mathrm{L}$ reaction mixtures consisting of $20 \mu \mathrm{L}$ of MasterMix and $5 \mu \mathrm{L}$ of extracted RNA. Reverse transcription and amplification conditions were $45^{\circ} \mathrm{C}$ for $10 \mathrm{~min}, 95^{\circ} \mathrm{C}$ for $10 \mathrm{~min}$, followed by 45 cycles of $95^{\circ} \mathrm{C}$ for $15 \mathrm{~s}$ and at $60^{\circ} \mathrm{C}$ for $45 \mathrm{~s}$. The quantitation curve for mengovirus RNA was achieved with four points $(0.1 \%, 1 \%, 10 \%$, and $100 \%)$ established with RNA extracted from $10 \mu \mathrm{L}\left(10^{6}\right.$ genomic copies) of a mengovirus solution (bioMérieux; Marcyl'Etoile, France), with the QIAamp viral RNA Mini kit (Qiagen; Hilden, Germany), according to the manufacturer's instructions. Values given are average results of two independent RT-qPCR amplifications. Whenever absence of amplification was observed, potential inhibitory effects of the RNA sample were checked by 1:5 and/or 1:10 dilutions, which were then subjected to new RT-qPCR amplifications. Positive and negative controls were always included in each RT-qPCR experiment, and the reactions only were validated when the quantification curves had the following characteristics: $R^{2}$ greater than 0.98 , slope between -3.1 and -3.6 , and efficiency between 90 and $115 \%$. Only samples with Cq values below 40 were considered positive. The results were expressed as percentage of recovery, according to the quantitation curve.

\subsection{Mengovirus Production in Cultured Cells and Infectivity Assays Performed at the End of the} Water Sampling Process

The replication of mengovirus for production of viral progeny and the evaluation of the infectivity recovered from the mengovirus solution applied in the water sampling processes, were performed in sub-confluent Vero E6 cultures (Vero C 1008, ATCC CRL-1586) grown in T25 flasks at $37^{\circ} \mathrm{C}$. Vero E6 cultures were routinely sub-cultured in maintenancemedium ( $\mathrm{CO}_{2}$ Independent Medium (Gibco, Thermo Fisher Scientific; Waltham, MA, USA) supplemented with $2 \mathrm{mM}$ GlutaMAX (Gibco, Thermo Fisher Scientific; Waltham, MA, USA), and $0.5 \mathrm{mg} / \mathrm{mL}$ gentamicin (Gibco, Thermo Fisher Scientific; Waltham, MA, USA)) that was supplemented with $10 \%$ inactivated fetal bovine serum (FBS) (Gibco, Thermo Fisher Scientific; Waltham, MA, USA).

For mengovirus production, a volume of $10 \mu \mathrm{L}$ (corresponding to $10^{6}$ genomic copies) previously thawed from a frozen $\left(-20^{\circ} \mathrm{C}\right)$ mengovirus solution (bioMérieux; Marcyl'Etoile, France) was incubated with the cells, after having been diluted in $1 \mathrm{~mL}$ of virus-production medium (maintenance medium supplemented with $2 \%$ FBS). After an incubation of the virus with the cells for two hours, $3 \mathrm{~mL}$ of virus-production medium was added, and the infected culture was maintained at $37^{\circ} \mathrm{C}$ and checked daily under a microscope Zeiss Axiovert 200 (Göttingen, Germany), until the appearance of cytopathic effect (CPE); images were recorded with a Zeiss AxioCam HRc digital camera and Axiovision program (München-Hallbergmoos, Germany). Then, the culture medium with detached cells was collected and clarified by low-speed centrifugation $(3000 \times g$ for $5 \mathrm{~min})$; the supernatant (mainly extracellular virions in suspension) was recovered, aliquoted and frozen at $-70{ }^{\circ} \mathrm{C}$.

For the detection of infectious mengovirus recovered at the end of the water sampling process, aliquots ( $1 \mathrm{~mL}$ ) of the subsamples reserved for the infectivity assays (see Section 2.1) were evaluated in cultured cells as described above and in Salvador et al. [23]. After four serial passages, the putative viral particles recovered in the clarified supernatants (about $4 \mathrm{~mL}$ ) of the infected cultures (mainly comprising extracellular virions of the 4th progeny) were frozen at $-70^{\circ} \mathrm{C}$ or immediately processed as described in 2.5 , for further RNA extraction. 


\subsection{Mengovirus Titration}

Mengovirus was titrated by inoculating serial 10-fold dilutions (made in virus production medium) of the virus suspension, into sub confluent Vero E6 cultures cultivated in 24-well plates (P24). After $2 \mathrm{~h}$ of incubation with the viral inoculum $(100 \mu \mathrm{L}), 500 \mu \mathrm{L}$ of virus-titration medium was added to each well, and the plates were incubated (avoiding any agitation) at $37^{\circ} \mathrm{C}$, for $36 \mathrm{~h}$. The virus-titration medium is the virus-production medium supplemented with 2\% Sephadex G50 fine (Merck KgaA, Darmstadt, Germany), sterilized before being added to the medium. The titration was stopped (targeting virus inactivation and fixation of viable cells) by addition of $500 \mu \mathrm{L}$ of $10 \%(v / v)$ formaldehyde, for $30 \mathrm{~min}$. The mixture culture medium/formaldehyde was properly discarded, the fixed cells were water washed and subsequently stained for $15 \mathrm{~min}$ with $0.1 \%(w / v)$ crystal violet in water; after discharge of the dye and washing with water, the plates were air dried. Viral plaques were counted, and the virus titers, expressed in PFU/mL (plaque forming units per $\mathrm{mL}$ ), were calculated according to the following: $\mathrm{PFU} / \mathrm{mL}=$ Average number of plaques $/ \mathrm{D} \times \mathrm{V}(\mathrm{D}=$ dilution where the viral plaques were counted; $\mathrm{V}=$ volume of the inoculum (0.1 $\mathrm{mL}$ in the present situation)).

\subsection{Extraction of Viral RNA from the Supernatants of Infected Cultures}

Aliquots of $4 \mathrm{~mL}$ from clarified suspensions of mengovirus as well as from the putative viruses produced from infectious mengovirus eventually recovered in the water sampling process (Section 2.3) were concentrated by centrifugation for $6 \mathrm{~h}$ at $17,000 \times \mathrm{g}$ and $4{ }^{\circ} \mathrm{C}$ to pellet the viral particles. The pellets were suspended in $140 \mu \mathrm{L}$ of PBS (Sigma-Aldrich, Merck; Darmstadt, Germany) and subjected to RNA extraction and to RT-qPCR evaluation, as described above in Section 2.2.

\subsection{Statistical Analysis}

Microsoft Excel 2017 (Microsoft Inc., Redmond, WS, USA) and IBM SPSS Statistics Version 27 (SPSS Inc., Chicago, IL, USA) were used to calculate the means, standard deviations, and Student's $t$-test. Student's $t$-test was applied to compare differences in the recovery of mengovirus, between the water matrices; differences were significant for $p$-values less than 0.05 .

\section{Results}

\subsection{Recovery Rates of Mengovirus Added after the Filtration/Primary Concentration Step}

In the 2018 pilot sampling, mengovirus was detected in the four samples analyzed (Table 1). In surface water, the average recovery rate of mengovirus RNA was $24.18 \%$ (SD of 6.14 ): $30.32 \%$ for the river and $18.04 \%$ for the dam reservoir (Table 1). In drinking water, the average recovery was $29.44 \%$ (SD of 9.36 ): $20.08 \%$ in water from WTP_R and $38.8 \%$ in water from WTP_D (Table 1).

Table 1. Mengovirus recovery rates in the water samples collected in the 2018 pilot sampling $(n=4)$ (addition of mengovirus after the filtration/primary concentration step).

\begin{tabular}{ccc}
\hline Water Matrix & Sampling Site & Mengovirus Recovery (\%) \\
\hline \multirow{2}{*}{ Surface water } & River & 30.32 \\
& Dam reservoir & 18.04 \\
\hline \multirow{2}{*}{ Drinking water } & WTP_R & 20.08 \\
& WTP_D & 38.80 \\
\hline
\end{tabular}

3.2. Recovery Rates of Mengovirus during the 2019 Sampling Campaign: Differences in Water Matrices

Out of the 25 surface water samples collected in 2019, mengovirus was detected and quantified in 11 with an average recovery of $0.09 \%(S D=0.29)$. The virus was detected in $5 / 16$ of the samples from the river (Figure 1A) with an average recovery of $0.10 \%$ 
$(\mathrm{SD}=0.28)$, and in $6 / 9$ samples from the dam reservoir, (Figure 1B) with an average recovery of $0.22 \%(S D=0.30)$. There was no pattern in the rates of recovery throughout the sampling campaign, except that most of the samples where mengovirus was not detected also presented RT-qPCR inhibition: nine out of 11 samples from the river and two out of from the three samples from the dam reservoir (Figure 1A,B; Table 2).
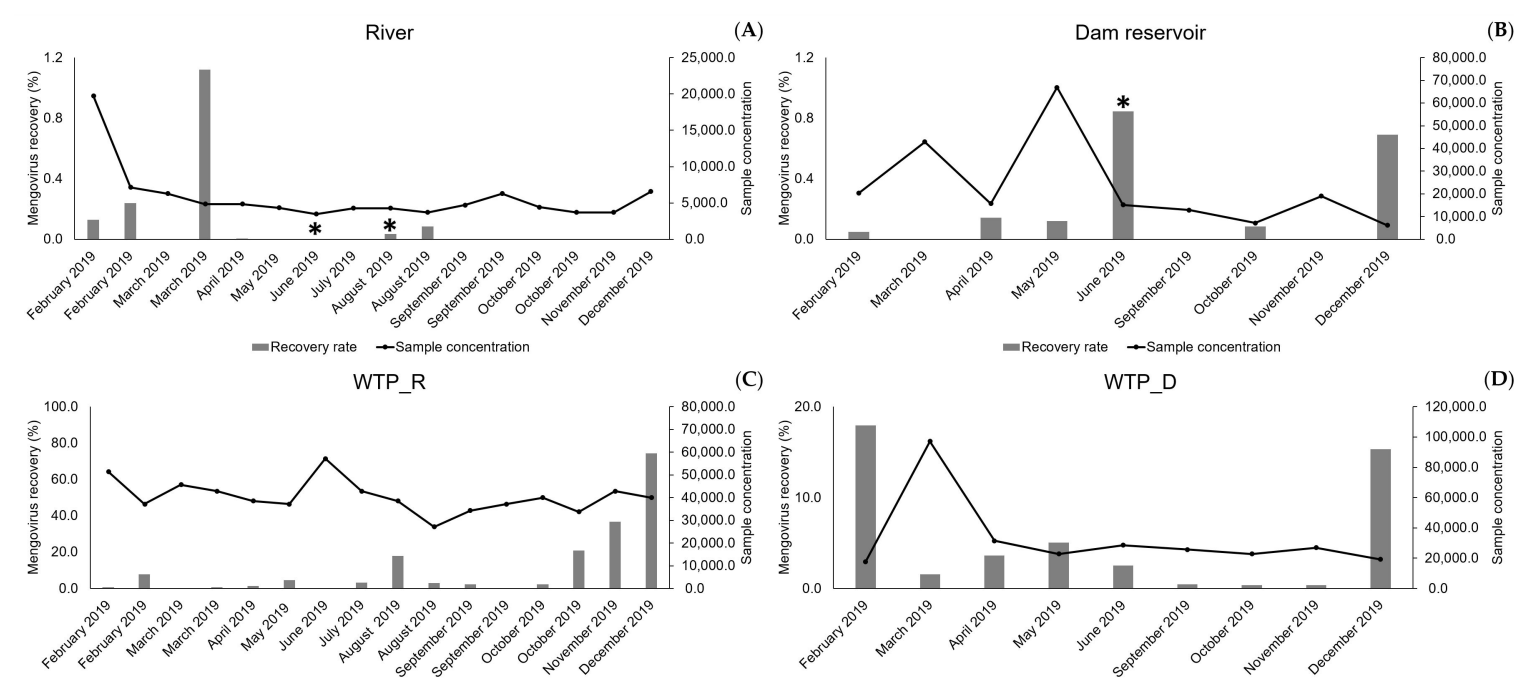

(C)

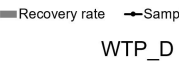

(D)

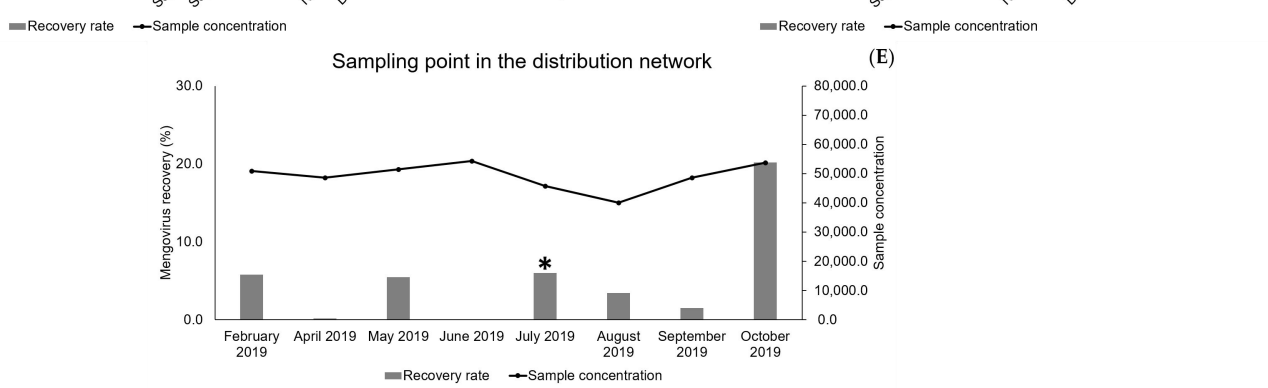

Figure 1. Mengovirus recovery rates and levels of water concentration, over the 2019 sampling campaign (addition of mengovirus during the filtration/primary concentration step), for the water collected at the five sampling points: (A) River $(n=16)$; (B) Dam reservoir $(n=9)$; (C) WTP_R $(n=16)$; (D) WTP_D $(n=9)$; (E) Sampling point in the distribution network $(n=9)$. The asterisks point to the three samples evaluated (and positive) for mengovirus infectivity.

Table 2. Data regarding the samples collected in the 2019 sampling campaign.

\begin{tabular}{ccccc}
\hline \multirow{2}{*}{ Water Matrix } & Sampling Site & Number of Samples & $\begin{array}{c}\text { Samples Presenting } \\
\text { RT-qPCR Inhibition }\end{array}$ & $\begin{array}{c}\text { Samples Positive for } \\
\text { Mengovirus RNA } \\
\text { (Average Recovery) }\end{array}$ \\
\hline \multirow{2}{*}{ Surface water } & River & 16 & $9(56.3 \%)$ & $5(0.1 \%)$ \\
\cline { 2 - 5 } & Dam reservoir & 9 & $2(22.2 \%)$ & $6(0.22 \%)$ \\
\hline \multirow{2}{*}{ Drinking water } & WTP_R & 16 & $0(0 \%)$ & $16(11.2 \%)$ \\
\cline { 2 - 5 } & \begin{tabular}{c} 
WTP_D \\
\cline { 2 - 5 } \\
\cline { 2 - 5 } \\
\cline { 2 - 5 } \\
Sampling point in ther distribution
\end{tabular} & 9 & $0(0 \%)$ & $7(4.0 \%)$ \\
\hline
\end{tabular}

Out of the 34 samples of drinking water analyzed in the three sampling points, mengovirus was detected and quantified in 32 with an average recovery of $7.84 \%$ ( $S D=14.14$ ). Mengovirus was detected in all the samples collected at the two WTPs, presenting an average recovery of $11.02 \%(\mathrm{SD}=19.06$ ) (ranging from $0.14 \%$ to $74.34 \%$ ) in the 16 samples from WTP_R (Figure 1C), and an average recovery of $4.00 \%(\mathrm{SD}=5.52)$ (ranging from $0.38 \%$ to $17.96 \%$ ) in the nine samples from WTP_D (Figure 1D). Finally, in the nine samples 
collected at the distribution point, the virus was detected in seven, with an average recovery of $4.72 \%(\mathrm{SD}=5.96)$ (ranging between $0.18 \%$ and $20.16 \%$ ). One of the two samples where mengovirus was not detected evidenced RT-qPCR inhibition (Figure 1E; Table 2).

There were statistically significant differences between the recovery rates obtained for the two analyzed water matrices ( $p$-value $=0.04$ ).

The level of concentration of the water samples at the end of the sampling process is also represented in Figure 1. It was variable throughout the sampling campaign, having been consistently higher in drinking water samples (from about 17,700 to 97,150-fold) than in surface water samples (from about 3700 to 66,900 -fold).

\subsection{Suitability of Mengovirus as Process Control Virus in Infectivity Assays}

Mengovirus was produced in Vero E6 cells grown in $\mathrm{CO}_{2}$ independent medium (Figure 2A), causing CPE (rounding and detaching of the cells) to the cultured cells (Figure 2B,C). The clarified supernatant of the infected culture displaying total CPE was titrated as described in Section 2.4, presenting a titer of $2 \times 10^{6} \mathrm{PFU} / \mathrm{mL}$, as shown in Figure 3.
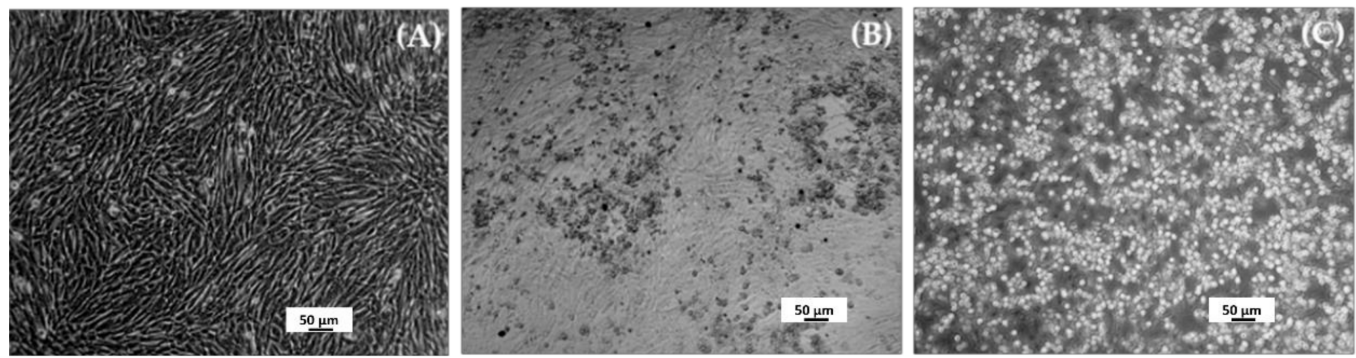

Figure 2. Photograph of Vero E6 cultures. (A) mock infected (control) culture evidencing a monolayer of adherent cells; $(\mathbf{B}, \mathbf{C})$ cultures infected with mengovirus, evidencing cytopathic effect (CPE): (B) early CPE (foci of infection), (C) complete CPE (rounded detached cells).

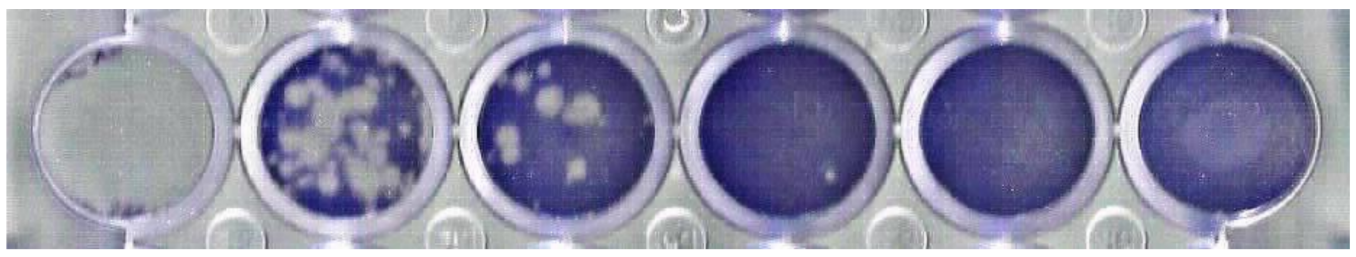

Figure 3. Mengovirus titration in Vero E6 cells cultivated in wells of a P24-well plate. Titration performed in virus-production medium $\left(\mathrm{CO}_{2}\right.$ independent medium supplemented with $2 \%$ fetal bovine serum) supplemented with $2 \%$ Sephadex G50. The wells were inoculated with $0.1 \mathrm{~mL}$ of the following dilutions of the virus: $10^{-2}, 10^{-3}, 10^{-4}, 10^{-5}$ (from left to right in the four first wells) and two controls were inoculated with $0.1 \mathrm{~mL}$ of virus-production medium (the two last wells). RNA extracted from the concentrated viral suspension produced in Vero E6 cells (corresponding to $4 \mathrm{~mL}$ of the viral suspension, i.e., $8 \times 10^{6} \mathrm{PFU}$ ) was RT-qPCR positive for mengovirus RNA (Cq value of 14.4 when evaluated by the RT-qPCR protocol also applied to the RNAs extracted from water samples).

\subsection{Detection of Infectious Mengovirus in Samples of Concentrated Water}

So far, until now there are no results concerning the recovery of infectious mengovirus in samples concentrated from artificially contaminated water, as in the 2019 sampling campaign and, from these, only a few (four samples) have been evaluated until now. Aliquots of these samples (Figure 1; Table 3), three from surface water (two from the river and one from the dam reservoir) and one from drinking water (the sampling point in the water distribution network), were inoculated into Vero E6 cultures. After three successive passages (on Vero E6 cultures) of the descendants of infectious viruses present in the inoculated water, the 4th putative viral progeny was concentrated by high-speed centrifugation and the pelleted viral particles were subjected to RNA extraction. RT-qPCR 
directed to these RNA samples evidenced positivity for mengovirus and $\mathrm{Cq}$ values between 11.7 and 14.2: the two river samples (of June and August) had Cq values of 12.9 and 14.2, respectively; the sample from the dam reservoir (of June) had a Cq of 12.7; the sample of July from the water distribution network had a Cq of 11.7 (Table 3). However, RNA extracted directly from these samples only evidenced recovery rates over $1 \%$ in the drinking water sample $(6.02 \%)$, and $0 \%$ recovery was observed in one sample from the river (June 2019), yet this could be attributed to inhibition of the RT-qPCR reactions (Table 3).

Table 3. Data regarding the samples assayed for mengovirus infectivity.

\begin{tabular}{|c|c|c|c|c|c|}
\hline Sampling Date & Matrix Type & Source & $\begin{array}{c}\text { Recovery of } \\
\text { Mengovirus RNA } \\
(\%)\end{array}$ & $\begin{array}{l}\text { Mengovirus } \\
\text { Infectivity }\end{array}$ & $\begin{array}{c}\text { RT-qPCR to } \\
\text { Mengovirus RNA } \\
\text { from Virions } \\
\text { Produced in Vero } \\
\text { E6 Cultures }\end{array}$ \\
\hline June 2019 & Surface water & River & $0.00 *$ & Positive & $\mathrm{Cq}=12.9$ \\
\hline June 2019 & Surface water & Dam reservoir & 0.84 & Positive & $\mathrm{Cq}=12.7$ \\
\hline July 2019 & Drinking water & $\begin{array}{c}\text { Sampling point in } \\
\text { the water } \\
\text { distribution } \\
\text { network }\end{array}$ & 6.02 & Positive & $\mathrm{Cq}=11.7$ \\
\hline August 2019 & Surface water & River & 0.08 & Positive & $\mathrm{Cq}=14.2$ \\
\hline
\end{tabular}

\section{Discussion}

In a complex and multistep procedure, it is important to understand whether and how deeply the procedures involved in each step influence the recovery rate. Thus, our analyses considered the addition of mengovirus at two steps of the sample processing. In a pilot sampling in 2018, the virus was added after the primary concentration, more precisely in the beef extract added just prior to the flocculation procedure. In the 2019 sampling campaign, it was considered more appropriate and informative to add mengovirus at a point involving the whole sample processing (i.e., at the filtration/primary concentration step) [23]. Comparing the two approaches tested, it was found that the procedure applied in the 2018 pilot sampling allowed higher recoveries (greater than $18 \%$ ) and produced identical results for the two water matrices, thus signifying that the greatest losses reflected in the recovery of virus' nucleic acids occur before the secondary concentration step, i.e., during the filtration/primary concentration step, and mainly in the sampling of surface water, as discussed below for the 2019 sampling campaign.

Recovery rates of 1\% or more are recommended in ISO 15216-1: 2017 [13] for bottled water and for much smaller volumes (about $5 \mathrm{~L}$ ) than the volumes sampled in the present study. Although there are no guidelines on the acceptable recovery values for surface water, the recovery rates registered for both water matrices in the 2018 pilot sampling may be considered acceptable.

In the 2019 sampling campaign mengovirus was not detected by RT-qPCR in 14 samples of surface water and, when detected and quantified (11), its recovery rate was usually under $1 \%$. These results can be explained by the large number of particles/contaminants found in the surface water of the two natural sources, which may interfere with the virus recovery by avoiding its binding to the filter. Moreover, the filtration/concentration of surface water was performed until the clogging of the filter membrane. This may have affected the filter properties, with implications for the adsorption of the control virus, whose addition only occurred in the final period of the filtration procedure when the contaminants were already highly concentrated in the filter, even in less contaminated water samples (Figure 1). This may explain why the "cleaner" water (allowing larger sampled volumes until filter clogging) did not evidence higher recovery rates of mengovirus, while the three highest values $(>0.7,<1.12)$ were found in less concentrated samples $(<20,000$-fold $)$ : two 
samples from the dam reservoir and one from the river (Figure 1). It is plausible that these values resulted from the existence of still some binding capacity of the filters, when mengovirus was added for filtration.

Concerning the samples from drinking water, mengovirus was detected in the large majority (32 out of 34), either collected at the outlet of the two WTPs or collected at the sampling point in the distribution network. With an average recovery rate of $7.84 \%$, and most samples (23 in 34) presenting recovery rates greater than $1 \%$, the implemented method and particularly the whole sampling process, provided acceptable recoveries, in accordance with ISO 15216-1: 2017 [13]. The 14 results showing recoveries under 1\% corresponded to higher volumes of filtered water ( $\geq 600$ L, i.e., samples concentrated more than 17,000-fold) (Figure 1), which may have affected the electropositive characteristics of the filter, eventually reducing its binding capacity in the final period of the filtration step (time of mengovirus addition). Although further studies will be necessary to test this hypothesis, taken together, these results allow proposing a limitation in the volumes when sampling water, particularly for natural surface water.

A few comparisons may be made with studies where mengovirus was added before/during the filtration step: Ishii et al. [27], based on samples of one liter of natural water, reported average recovery rates $(9.4 \%)$ higher than in the present study (under $1 \%)$; however, ranging from more extreme values ( $0.04 \%$ to $69.5 \%)$; in Petterson et al. [28], the average recovery rate in drinking water collected at the outlet of a WTP was $1.2 \%$, lower than in the present study (7.84\%); in Teixeira et al. [15], the recovery rates reported for a diversity of water matrices, drinking water included, were less than $10 \%$. These three studies involved sampling volumes far from those contemplated in our surveys and support the suggestion of using narrow sample volumes.

The significant differences between the recovery rates in the two water matrices, found in the present study (confirmed by the application of the Student's $t$-test), may be due to their very diverse characteristics. The surface water, having not undergone any treatment, contains a higher number of suspended particles and other agents that will be concentrated in the filter, while the drinking water was previously treated by processes that allowed the removal of suspended particles [10]. Consequently, the conditions for mengovirus adhesion to the filter will be different in the two situations, less efficient when surface water is collected. Hennechart-Collette et al. [24] also reported that the recovery rate of mengovirus is strongly influenced by the matrix under analysis (food or water).

In addition, RNA degradation of the process control virus and/or inhibition of the RT-qPCR reaction, might also influence the recovery rates evaluated through this molecular approach; these situations are strongly influenced by the contaminants co-concentrated with the sampled water along the sampling procedures and natural surface waters are most frequently associated with such contaminants $([9,29]$. Our results strongly support this statement because: (i) RT-qPCR inhibition was associated with many samples (12 from a total of 59), most of them from surface water (11 from 25); (ii) absence of mengovirus detection was closely associated with RT-qPCR inhibition, since this relationship only was not verified for four samples: three from surface water and one from drinking water. Moreover, it is worth noting that our results concerning the detection of mengovirus infectivity in the sampled water, although only reported in four samples, allowed us to find infectious mengovirus (able to replicate in Vero E6 cultures) in all of them, even in one sample where viral RNA could not be detected; this result is in accordance with the previous findings and suggests that the monitoring of viral infectivity has great potential that should be taken into account.

Although a process control virus is highly recommended for the validation and interpretation of water monitoring processes $[10,18,30]$, the low RNA recovery rates obtained for surface water in the present study recommend considering the addition of mengovirus only at the stages following the primary concentration step, where it will still be very useful, namely as control of RNA extraction (as initially proposed in the PCT/EP2007/055407 patent [17]). Furthermore, knowing that mengovirus induces cytopathic effects on Vero 
E6 cells (this study) and HeLa cells [24,28], its addition at the beginning of the process can make it difficult to interpret assays aiming the evaluation of the infectivity potential (for other virus) of the samples under survey, since the appearance of CPE may be exclusively due to the presence of mengovirus.

On the other end, the achievement of accurate replication and titration of mengovirus in Vero E6 cultures, which recently allowed researchers to show the recovery of infectious hepatitis E virus (HEV) from both water matrices targeted in the present study, was one of the main points of relevance [23]. No less relevant was the mengovirus recovery in an infectious state from the four samples so far evaluated for that purpose, associated with the fact that those samples were already found to be positive for infectious HEV [23], which was confirmed again (except for the drinking water sample) in the present study (Cq values below 36) (data not shown).

Taken together, these results allow anticipating the reliability of infectivity assays in future virus surveys where mengovirus and Vero E6 cultures may work together in the control of the processes to be implemented, particularly when the targets are enteric viruses (e.g., HEV, Norovirus) and other viruses able to replicate in this cell line (e.g., SARS-CoV2).

\section{Conclusions}

The recovery rates of mengovirus RNA were dependent on the step where its addition occurred and on the type of water matrix to which it was added during the initial step of sampling, since significantly higher recovery rates were only found in both water matrices when mengovirus was added after the filtration/primary concentration step.

Although this study evidenced the usefulness of mengovirus in the validation of the experimental procedures implemented for the monitoring of enteric viruses in surface and drinking waters, further evaluations are still needed to obtain a more accurate confirmation of mengovirus as a control of sampling processes in water monitoring.

Mengovirus replication and titration in Vero E6 cultures, and the confirmation of the presence of infectious mengovirus in the sampled water, anticipate its future suitability and promise as control in surveys extended to the evaluation of viral infectivity.

Author Contributions: Conceptualization, C.N., M.F.C. and D.S.; methodology, C.N., M.F.C. and D.S.; validation, D.S., M.F.C. and C.N.; formal analysis, D.S., C.N. and M.F.C.; investigation, D.S., C.N. and M.F.C.; resources, D.S., C.N. and M.F.C.; data curation, D.S.; writing-original draft preparation, D.S.; writing-review and editing, M.F.C., C.N. and R.N.C.; visualization, D.S., M.F.C. and C.N.; supervision, C.N. and M.F.C.; project administration, C.N., M.F.C. and D.S.; funding acquisition, M.F.C., C.N. and R.N.C. All authors have read and agreed to the published version of the manuscript.

Funding: This work was supported by Foundation for Science and Technology (FCT) Portugal and Empresa Portuguesa das Águas Livres (EPAL) through a Ph.D. grant to D. Salvador (PDE/BDE/114582/2016) and FCT/MCTES projects (UIDP/50017/2020+UIDB/50017/2020 and UIDB/04295/ 2020+UIDP/04295/2020) through national funds.

Institutional Review Board Statement: Not applicable.

Informed Consent Statement: Not applicable.

Data Availability Statement: The data of this study are available on request from the corresponding author (daniel.salvador@adp.pt).

Acknowledgments: The authors are also grateful to the microbiology team of the Lisbon Laboratory of EPAL for all help in implementing the method, to Mariana Santinho (MARE-Marine and Environmental Sciences Centre) for valuable contribution in photo capturing; ISAMB and FranciscoAntunes for financial support; and Francisco Caeiro for providing helpful comments and English revision.

Conflicts of Interest: The authors declare no conflict of interest. 


\section{References}

1. World Health Organization. Guidelines for drinking-water quality: Fourth edition incorporating the first addendum. WHO Libr. Cat. Data 2017, 1-541. Available online: https:/ / www.who.int/publications/i/item/9789241549950 (accessed on 15 June 2021).

2. Schwarzenbach, R.P.; Egli, T.; Hofstetter, T.B.; von Gunten, U.; Wehrli, B. Global Water Pollution and Human Health. Annu. Rev. Environ. Resour. 2010, 35, 109-136. [CrossRef]

3. Rodríguez-Lázaro, D.; Cook, N.; Ruggeri, F.M.; Sellwood, J.; Nasser, A.; Nascimento, M.S.J.; D’Agostino, M.; Santos, R.; Saiz, J.C.; Rzezutka, A.; et al. Virus hazards from food, water and other contaminated environments. FEMS Microbiol. Rev. 2012, 36, 786-814. [CrossRef] [PubMed]

4. Chen, L.; Deng, Y.; Dong, S.; Wang, H.; Li, P.; Zhang, H.; Chu, W. The occurrence and control of waterborne viruses in drinking water treatment: A review. Chemosphere 2021, 281, 130728. [CrossRef] [PubMed]

5. Teixeira, P.; Salvador, D.; Brandão, J.; Ahmed, W.; Sadowsky, M.J.; Valério, E. Environmental and adaptive changes necessitate a paradigm shift for indicators of fecal contamination. Microbiol. Spectr. 2020, 8, 1-20. [CrossRef]

6. $\quad$ Eifan, S.A. Enteric Viruses And Aquatic Environment. Internet J. Microbiol. 2013, 12, 1-7.

7. Rzezutka, A.; Cook, N. Survival of human enteric viruses in the environment and food. FEMS Microbiol. Rev. 2004, 28, 441-453. [CrossRef] [PubMed]

8. Cuevas-Ferrando, E.; Randazzo, W.; Pérez-Cataluña, A.; Sánchez, G. HEV Occurrence in Waste and Drinking Water Treatment Plants. Front. Microbiol. 2020, 10, 2937. [CrossRef]

9. Haramoto, E.; Kitajima, M.; Hata, A.; Torrey, J.R.; Masago, Y.; Sano, D.; Katayama, H. A review on recent progress in the detection methods and prevalence of human enteric viruses in water. Water Res. 2018, 135, 168-186. [CrossRef]

10. Salvador, D.; Caeiro, M.F.; Serejo, F.; Nogueira, P.; Carneiro, R.N.; Neto, C. Monitoring waterborne pathogens in surface and drinking waters. Are Water Treatment Plants (WTPs) simultaneously efficient in the elimination of enteric viruses and fecal indicator bacteria (FIB)? Water 2020, 12, 2824. [CrossRef]

11. Masclaux, F.G.; Hotz, P.; Friedli, D.; Savova-Bianchi, D.; Oppliger, A. High occurrence of hepatitis E virus in samples from wastewater treatment plants in Switzerland and comparison with other enteric viruses. Water Res. 2013, 47, 5101-5109. [CrossRef]

12. Fout, G.S.; Brinkman, N.E.; Cashdollar, J.L.; Griffin, M.; McMinn, B.R.; Rhodes, E.R.; Varughese, E.A.; Karim, M.R.; Grimm, A.C.; Spencer, S.K.; et al. Method 1615-Measurement of Enterovirus and Norovirus Occurrence in Water by Culture and RT-qPCR; U.S. Environmental Protection Agency: Cincinnati, OH, USA, 2014; pp. 1-105.

13. ISO International Standard. Microbiology of the Food Chain-Horizontal Method for Determination of Hepatitis A Virus and Norovirus; ISO Copyright Office: Geneva, Switzerland, 2017. Available online: https://www.iso.org/standard/65681.html (accessed on 10 July 2021).

14. Gentry-Shields, J.; Jaykus, L.-A. Comparison of Process Control Viruses for use in Extraction and Detection of Human Norovirus from Food Matrices. Food Res. Int. 2015, 77, 320-325. [CrossRef]

15. Teixeira, P.; Costa, S.; Brown, B.; Silva, S.; Rodrigues, R.; Valério, E. Quantitative PCR detection of enteric viruses in wastewater and environmental water sources by the Lisbon municipality: A case study. Water 2020, 12, 544. [CrossRef]

16. ICTV Picornaviridae. Available online: https://talk.ictvonline.org/ictv-reports/ictv_online_report/positive-sense-rna-viruses/ picornavirales/w/picornaviridae (accessed on 25 June 2021).

17. World Intellectual Property Organization WO 2008/145197. Available online: https:// patentimages.storage.googleapis.com/ae/ 7d/f2/a42b0c3d42127e/WO2008145197A1.pdf (accessed on 21 June 2021).

18. Farkas, K.; Cooper, D.M.; McDonald, J.E.; Malham, S.K.; de Rougemont, A.; Jones, D.L. Seasonal and spatial dynamics of enteric viruses in wastewater and in riverine and estuarine receiving waters. Sci. Total Environ. 2018, 634, 1174-1183. [CrossRef]

19. Silva, A.K.; Le Saux, J.C.; Parnaudeau, S.; Pommepuy, M.; Elimelech, M.; Le Guyader, F.S. Evaluation of removal of noroviruses during wastewater treatment, using real-time reverse transcription-PCR: Different behaviors of genogroups I and II. Appl. Environ. Microbiol. 2007, 73, 7891-7897. [CrossRef] [PubMed]

20. BioMérieux. Mengo Extraction Control Kit. 2016, pp. 1-5. Available online: https://tools.thermofisher.com/content/sfs/ manuals/Mengovirus_Process_Control_4475931.pdf (accessed on 10 May 2021).

21. Coudray-Meunier, C.; Fraisse, A.; Martin-Latil, S.; Guillier, L.; Delannoy, S.; Fach, P.; Perelle, S. A comparative study of digital RT-PCR and RT-qPCR for quantification of Hepatitis A virus and Norovirus in lettuce and water samples. Int. J. Food Microbiol. 2015, 201, 17-26. [CrossRef] [PubMed]

22. Randazzo, W.; Truchado, P.; Cuevas-Ferrando, E.; Simón, P.; Allende, A.; Sánchez, G. SARS-CoV-2 RNA in wastewater anticipated COVID-19 occurrence in a low prevalence area. Water Res. 2020, 181, 115942. [CrossRef] [PubMed]

23. Salvador, D.; Neto, C.; Benoliel, M.J.; Filomena Caeiro, M. Assessment of the presence of hepatitis E virus in surface water and drinking water in Portugal. Microorganisms 2020, 8, 761. [CrossRef]

24. Hennechart-Collette, C.; Martin-Latil, S.; Guillier, L.; Perelle, S. Determination of which virus to use as a process control when testing for the presence of hepatitis A virus and norovirus in food and water. Int. J. Food Microbiol. 2015, 202, 57-65. [CrossRef]

25. Cuevas-ferrando, E.; Pérez-cataluña, A.; Allende, A.; Guix, S.; Randazzo, W.; Sánchez, G. Recovering coronavirus from large volumes of water. Sci. Total Environ. J. 2021, 762, 143101. [CrossRef]

26. Pérez-cataluña, A.; Cuevas-ferrando, E.; Randazzo, W.; Falcó, I.; Allende, A.; Sánchez, G. Comparing analytical methods to detect SARS-CoV-2 in wastewater. Sci. Total Environ. 2021, 758, 143870. [CrossRef] 
27. Ishii, S.; Kitamura, G.; Segawa, T.; Kobayashi, A.; Miura, T.; Sano, D.; Okabe, S. Microfluidic quantitative PCR for simultaneous quantification of multiple viruses in environmental water samples. Appl. Environ. Microbiol. 2014, 80, 7505-7511. [CrossRef]

28. Petterson, S.; Grøndahl-Rosado, R.; Nilsen, V.; Myrmel, M.; Robertson, L.J. Variability in the recovery of a virus concentration procedure in water: Implications for QMRA. Water Res. 2015, 87, 79-86. [CrossRef] [PubMed]

29. Zulkifli, S.; Rahim, H.; Lau, W. Detection of contaminants in water supply: A review on state-of-the-art monitoring technologies and their applications. Sens. Actuators B Chem. 2018, 255, 2657-2689. [CrossRef] [PubMed]

30. Londoñe-bailon, P.; Sánchez-robinet, C. Efficiency evaluation of the process control virus "Mengovirus" in real time RT-PCR viral detection in the bivalve mollusc Donax sp. J. Virol. Methods 2018, 262, 20-25. [CrossRef] [PubMed] 